\title{
Erratum to: Selenium-Enriched Probiotics Improves Murine Male Fertility Compromised by High Fat Diet
}

\author{
Hala A. M. Ibrahim • Yongxing Zhu • Cong Wu • \\ Chenhui Lu • Michael O. Ezekwe • Shengfa F. Liao • \\ Kehe Huang
}

Published online: 12 February 2012

(C) Springer Science+Business Media, LLC 2012

\section{Erratum to: Biol Trace Elem Res}

DOI 10.1007/s12011-011-9308-2

The original version of this article unfortunately contained mistakes. The name of "Kehe Haung" is now corrected in the author group of this article. Also, the description of the analytical method of "Serumal Testosterone" in the section of "Materials and Methods: Laboratory Analyses" should read "Total serumal testosterone concentration was determined by a radioimmunoassay using a commercial assay kit (Beijing Atom Hightech Co, Ltd., Beijing, China) on an automated analyzer (UniCel ${ }^{\mathrm{TM}}$ DxI 800, Beckman, USA) in accordance with the manufacturers' instructions." The original sentence, "The commercial kit used for determination of serumal T3 and T4 concentration was the Coat-A Count RIA total T3 \& T4 kit purchased from Beijing North Institute of Biological Technology (Beijing, China) and used according to the manufacturer's instructions." should be deleted.

The online version of the original article can be found at http://dx.doi. org/10.1007/s12011-011-9308-2.

H. A. M. Ibrahim $\cdot$ Y. Zhu $\cdot$ C. Wu $\cdot$ C. Lu $\cdot$ K. Huang $(\bowtie)$

Institute of Nutritional and Metabolic Disorders of Domestic

Animals and Fowls, Nanjing Agricultural University,

Nanjing 210095, China

e-mail: khhuang@njau.edu.cn

H. A. M. Ibrahim

Department of Pathology, College of Veterinary Medicine,

Sudan University of Science and Technology,

P. O. Box 204, Khartoum North, Sudan

M. O. Ezekwe $\cdot$ S. F. Liao $(\bowtie)$

Department of Agriculture, Alcorn State University,

Alcorn State, MS 39096-7500, USA

e-mail: liao@alcorn.edu 